Aletria, Belo Horizonte, v. 30, n. 1, p. 31-43, 2020

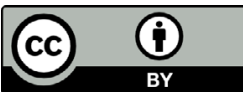

\title{
A sociologia e o entre-lugar
}

\section{Sociology and the Space in-Between}

\author{
Elide Rugai Bastos \\ Universidade Estadual de Campinas (UNICAMP), Campinas, São Paulo / Brasil \\ eliderugai@uol.com.br \\ http://orcid.org/0000-0002-3193-9438
}

Resumo: O texto afirma que Uma literatura nos trópicos, de Silviano Santiago, publicado em 1978, desafia a sociedade e a cultura brasileiras a se repensarem, tarefa difícil naquela conjuntura marcada pelas trevas. Centra-se no primeiro capítulo do livro, "O entre-lugar do discurso latino-americano", para mostrar que a proposta do autor provoca a abertura de espaço para acolher esse desafio e alimenta a coragem para enfrenta-lo. Questionando a intransigência com o que destoa da norma estabelecida, do comportamento rotinizado, a categoria entre-lugar permite abandonar a ideia de unidade, pureza, homogeneidade cultural e introduzir a obrigatoriedade de reflexão sobre a alteridade e a heterogeneidade, conceitos que arejaram o pensamento contemporâneo. Ilustro esse papel na área das ciências sociais, em especial na sociologia. A expressão entre-lugar tornou-se instrumento fundamental para compreendermos o lugar da sociologia brasileira no cenário das ciências sociais cosmopolitas.

Palavras-chave: Silviano Santiago; entre-lugar; sociologia brasileira; colonialismo cultural; literatura latino-americana.

Abstract: The text states that Silviano Santiago's Uma literatura nos trópicos, published in 1978, challenges Brazilian society and culture to rethink themselves, a difficult task in that dark conjuncture. It focuses on the first chapter of the book, "O lugar do discurso latino-americano", to show that the author's proposal boldly poses and addresses the challenge of revising Brazilian society. Questioning the established norm of the routine behavior, the "space in-Between" category allows us to abandon the idea of unity, purity and cultural homogeneity. Thus, it is mandatory to reflect on otherness and heterogeneity, concepts that renew contemporary thinking. I illustrate 
this issue considering social sciences, especially in sociology. The concept of "space in-Between" has become a fundamental instrument for understanding the place of Brazilian Sociology in the cosmopolitan setting of the Social Sciences.

Keywords: Silviano Santiago; space in-between; Brazilian Sociology; cultural colonialism; Latin American literature.

O ano de 1968, sem dúvida, representa um marco de mudanças sociais, culturais e políticas que levaram o mundo a uma revisão de valores, em especial, daqueles conservadores. Maio de 68 é um momento de emergência clara desse quadro, que vinha anunciado por reivindicações e mudança de comportamentos que colocavam em questão a ordem estabelecida. As análises sobre o período divergem sobre as conquistas objetivas, mas percebemos um processo que legitimou transformações na sociedade, direcionadas à exigência de revisão dos direitos humanos em várias de suas facetas e concretizada, diferentemente, em locais e tempos diversos.

Essa reordenação e busca de formas para operacionalizá-la aparece no pensamento latino-americano expressando-se na literatura e nas ciências sociais do período, embora, naquele momento, envolvidas em névoas sobre seu encaminhamento decorrentes do clima político autoritário. Ilustro esse clima com frase de Júlio Cortázar do capítulo sessenta e dois de $O$ jogo da amarelinha, livro publicado em 1968. "Os atores pareciam loucos ou totalmente idiotas [...] porque neles, algo que o homo sapiens guarda no subliminar abriria penosamente um caminho como se um terceiro olho pestanejasse penosamente debaixo do osso frontal." (CORTAZAR, 1972, p. 317).

Esse capítulo se encontra na parte do livro intitulada "De outros lados", acompanhada da anotação do autor "Capítulos prescindíveis". Creio que de modo algum são prescindíveis, uma vez que neles, Cortázar afronta dilemas sobre as ideias, sua reflexão e adequação ao tempo e ao espaço: ideias vistas como "forças habitantes, estrangeiras, que avançam em busca do seu direito de cidadania”. (CORTAZAR, 1972, p. 316). Evidentemente, afirmar que são textos prescindíveis para a armadura do livro se trata de estratégia do escritor para o questionamento de concepções sobre o processo cognitivo, ancoradas no dualismo, colocando a dúvida metódica diferentemente da bipolaridade cartesiana. Tanto assim, que seu livro imediatamente posterior, intitulado 62 modelo para armar (primeira 
edição de 1968), funda-se na provocação levantada naquele capítulo e reforça a importância da tese antidualista. Um desassossego contínuo atravessa o texto, no sentido da desconstrução daquele modelo e na busca de outro espaço não só para alocar as ideias como para compreender os desacertos do narrador ao situar-se em contexto que não lhe é originário. Indaga: a dúvida é legítima? Como expressá-la num universo em que os significados já estão dados? Consciente ou inconscientemente trata-se de preocupação constante do(s) escritor(es) latino-americano(s), buscando alocar-se em um quadro intelectual que o(s) posiciona como portador(es) de valores gerados fora dos "centros civilizados", em um lugar de pouca credibilidade. Voltarei mais adiante a essa questão.

A frase citada trouxe à lembrança o tuatara, nome maori de réptil da Nova Zelândia, cuja origem data de milhões de anos. Dotado de três olhos de estrutura normal, tem, porém, o terceiro, posicionado entre os outros dois, coberto de escamas que bloqueiam a passagem total da luz, mas que é usado para distinguir luminosidade e sombra. Sua função é complementar - ajuda-o a fugir da luz em direção à sombra, ambiente preferido por ele - mas, talvez sua existência tenha sido a razão de sua sobrevivência enquanto cerca de $70 \%$ dos animais, como os dinossauros, foram aniquilados há milhões de anos. Esse animal é normalmente associado a lagartos, crocodilos e aves, porém não é classificado especificamente como um deles. Sua família remonta a 225 milhões de anos, tornando-o uma espécie de "fóssil vivo". Por isso, os debates entre os cientistas para definir "sua identidade animal" que não se encaixa aos padrões estabelecidos pela ciência. Essa mesma dificuldade de classificação atinge grande parte da obra dos intelectuais latino-americanos, marcando-a com indecisão sobre o lugar que ocupa no conjunto da cultura mundial. Por isso, portadores de um terceiro olho, sugerido por Cortázar, derivado do embate com o colonialismo cultural, lhes é permitido ver a partir de outra dimensão, que não anula as outras existentes.

\section{O tema e seu cenário}

É a afirmação da fragilidade da aplicação de padrões universais que preside a temática de 62 modelo para armar. $\mathrm{O}$ risco dessa ousadia leva o intelectual/narrador a pestanejar na tentativa de fixar-se numa direção. Sendo um traço subliminar, como vemos na frase citada, coloca-o em um locus não definido que, frequentemente, explica sua insegurança, 
e reforça o aspecto indagador de seu perfil e o faz levantar perguntas que parecem estranhas, pois não têm respostas imediatamente codificadas.

Meu retorno à leitura desses textos de 1968 foi provocado pelo livro de Silviano Santiago, Uma literatura nos trópicos, publicado em 1978, em especial pelo primeiro ensaio, intitulado "O entre-lugar do discurso latino-americano", onde relembra passagem muito significativa de Cortázar (SANTIAGO, 2000, p. 22). Juan, um argentino em Paris, na véspera de Natal vai ao restaurante Polidor para jantar. O maître o coloca na mesa que se encontra ao fundo do restaurante e o instala de costas para o público, de frente a um espelho. Aguardando ser atendido, ouve o pedido de outro frequentador - "Je voudrais un château saignant" - e traduz mentalmente - "Eu queria um castelo sangrento". Juan, tradutor por profissão, sabia perfeitamente que o cliente gordo se referia a um bife mal passado. Mais ainda, tinha consciência de que entre os presentes era o único que conferia ao pedido um duplo sentido. A simples ocorrência o faz refletir como uma mesma frase pode ter um sentido diverso conforme o lugar em que é pronunciada, ouvida ou interpretada. Ao mesmo tempo, de costas para o público, o lugar que ocupava permite-lhe ver que o jornal France Soir, aberto por comensal vizinho, mostra as manchetes no falso alfabeto russo dos espelhos. Tem consciência de que a dupla inversão, da linguagem e da imagem, talvez provocada pelo livro que acabara de comprar, o coloca e o explica em situação sui generis: é um sul-americano em Paris. ${ }^{1}$

Juan reflete: como colocar em palavras e definir a seus amigos essa sensação de "sem lugar" que o assalta? Pergunta-se: porque escolheu o restaurante Polidor para jantar em dia tão significativo? porque pedira automaticamente o prato coquille Saint-Jacques? ainda, o vinho alsaciano Sylvaner? Embora não explicite, estas escolhas traduzem um conjunto de tradições francesas, que têm pouco significado para ele, mas que cumpre quase como rotina, uma espécie de reconhecimento de superioridade dessa tradição. ${ }^{2}$

\footnotetext{
${ }^{1}$ Trata-se de um livro de Michel Butor, cujo título não é citado. Juan comenta as referências a Chateaubriand. Pode-se inferir que seja o livro Répertoire II, de 1964, onde foi reapresentado o artigo "Chateaubriand et l'ancienne Amérique", anteriormente publicado na Nouvelle Revue Française, v. 132, p. 1015-1031, dez. 1963.

${ }^{2}$ Polidor é o bistrô mais antigo de Paris. Fundado em 1845, o lugar conserva a mesma estrutura, decoração e estilo de serviço desde a inauguração. Segundo parece, teve uma clientela ilustre: André Gide, James Joyce, Ernest Hemingway, Antonin Artaud e Paul Valéry. Coquilles Saint-Jacques é prato tradicional da cozinha francesa, vieiras com
} 
Afirmei que o conjunto dessas tradições pouco representa para Juan: ele reclama do ambiente sombrio do restaurante, das mulheres idosas de óculos que o servem, do pouco atrativo da comida, e do café, que considera o pior de Paris. Portanto questiona: porque atribuo valor àquilo que nada significa para mim?

\section{Escritor e leitor latino-americanos: uma provocação}

A partir da ideia de inversão e insegurança, reconhecida no exemplo da passagem narrada por Cortázar, Silviano Santiago abre a reflexão que se estende pelos diversos ensaios do livro Uma literatura nos trópicos. A meu ver, há uma expressão do autor que traduz o eixo articulador dos diversos capítulos: "Em todo caso, uma coisa é certa: as leituras do escritor latino-americano não são nunca inocentes. Não poderiam nunca sê-lo." (SANTIAGO, 2000, p. 22).

Em Cortázar, a articulação das situações vividas por Juan fica sem resposta, envolvida na dúvida que o atormenta. Em outros termos, fica por conta das exigências que o autor faz a seu leitor, afinal, trata-se de ficção. Silviano desde o início de Uma literatura nos trópicos esclarece o tema e o objetivo de suas reflexões. Toma a passagem do escritor argentino para ilustrar a amplitude da questão já colocada via metáfora de Montaigne sobre a luta do rei Pirro com os romanos: "a marca do conflito eterno entre o civilizado e o bárbaro, entre o colonialista e o colonizado, entre Grécia e Roma, entre Roma e suas províncias, entre a Europa e o novo Mundo, etc." (SANTIAGO, 2000, p. 10).

Seguindo essa linha, o ensaio "O entre-lugar do discurso latinoamericano" desdobra-se em reflexões que ancoram os outros capítulos. Cito algumas delas: o questionamento do conceito de superioridade; a busca de libertação de noções que impõem a ideia de continuidade; a negação da validade do fenômeno de duplicação; o desvio da norma como transfigurador dos valores vistos como imutáveis. A partir desses

molho branco servidas em sua própria casquinha. Sylvaner, vinho branco que costuma acompanhar frutos do mar, é da Alsácia, região que foi objeto de lutas com a Alemanha e tornou-se francesa. Seus vinhedos localizam-se ao lado do Rio Reno, que define a fronteira entre França e Alemanha.

${ }^{3}$ Trata-se de Pirro, rei de Éfeso, que considerava os romanos bárbaros, mas se surpreende com a organização de seu exército. Vence a batalha com grandes perdas, o que enfraquece seu poder, e acaba por marcar o início de sua decadência. 
pontos funda uma provocação: "os bárbaros não se comportam como tais.” (SANTIAGO, 2000, p. 10).

Comento brevemente essas questões, que partem de um deslocamento do olhar em relação às perspectivas admitidas como normais/ corretas/verdadeiras e aos direcionamentos considerados imutáveis quanto à atribuição do lugar a ser ocupado pelos atores, seja na estrutura social, na cultura ou na política. Por isso a lembrança inicial de um terceiro olho, que em certo momento permite aos escritores localizados na margem do sistema perceber esse preconceito e, às vezes, agir contra ele.

$\mathrm{O}$ exame das questões, uma vez que o dualismo não responde a situações concretas, faz com que Silviano avance instrumento para seu enfrentamento: é a proposta do entre-lugar. Sumarizo a partir de exemplo dado pelo autor: referindo-se aos primeiros momentos da colonização da América Latina, aponta o colonizador impondo seu poderio, sua língua, seus valores, afirmando a "superioridade" de sua cultura, elementos que bem ou mal acabam fazendo parte da vivência do colonizado. No entanto, este pode subverter seu sentido, de maneira que aqueles costumes e modo de vida sejam adaptados à sua condição e a seus interesses. Mais do que isso, testando concretamente se a superioridade dos valores adventícios é real. Silvano ilustra invocando passagem de Lévi-Strauss em Tristes Trópicos sobre os índios de Porto Rico. ${ }^{4}$

Passando a momentos posteriores, uma vez que a adoção dos valores da metrópole se faz pelo "uso arbitrário da violência e a imposição brutal de uma ideologia" (SANTIAGO, 2000, p.14), configura-se uma aparente unidade, pois se apagam os traços originais pelo esquecimento de sua origem. Assim, a duplicação passa a ser a medida da civilização. Nas palavras de Silviano Santiago "a América transforma-se em cópia, simulacro que se quer mais e mais semelhante ao original" (SANTIAGO, 2000, p. 14).

No século XX, o neocolonialismo vem a ser questionado, principalmente se pensarmos a partir de meados dos anos 1950. Nesse momento, emerge a questão do desenvolvimentismo, com a força de uma proposta de homogeneização do processo - CEPAL - para os países

\footnotetext{
${ }^{4}$ Os índios "se dedicam à captura de brancos com o intuito de os matar por imersão. Em seguida, durante semanas ficam de guarda em torno dos afogados para saber se eles se submetem ou não às leis de putrefação." (SANTIAGO, 1976, p. 12). É seu teste para verificar se os colonos são humanos ou são deuses.
} 
da América Latina. Essa proposição não é única, mas hegemônica. Traz como fundamento uma visão dual da sociedade. Exemplo dessa formulação é a afirmação da existência de dois Brasis, apresentada no artigo de Jacques Lambert (1959). Contrariando essa análise aparecem vários intelectuais que se agregam a movimentos intelectuais que propõem desvio da norma cepalina. Lembro romancistas, antropólogos e sociólogos, mas há certamente uma mobilização ampla que envolve músicos, artistas plásticos, arquitetos, entre outros. Romancistas como Guimarães Rosa, Alejo Carpentier, Juan Rulfo, Garcia Marquez; Juán Carlos Onetti; sociólogos e antropólogos como Darcy Ribeiro, Florestan Fernandes, Costa Pinto, Guerreiro Ramos, Pablo Gonzáles Casanova, Gino Germani, Arthur Rios, Edison Carneiro, Jorge Graciarena, entre outros, se empenharam nessa direção. Representam a transgressão e a destruição dos conceitos unidade e pureza, que negam a diversidade e a diferença - étnica, cultural, sexual, religiosa. Pagaram alto preço por essa façanha, bem como a sociedade que representavam, conhecendo a repressão e a tortura que se instalaram com as ditaduras. A simples lembrança desses nomes, o sentido de sua reflexão e produção, as condições que marcaram a interrupção de seu itinerário intelectual mostram a atualidade do livro de Silviano Santiago publicado há 40 anos, reunindo textos escritos a partir de 1969.

Nele, coloca perguntas que nos assaltam: qual a atitude a ser tomada pelo intelectual de um país em evidente inferioridade econômica em relação a grande parte do Ocidente, à cultura da metrópole, e à própria pluralidade cultural do país? A única forma de avaliação de seu trabalho seria medi-lo pelo modelo importado dos centros metropolitanos? $\mathrm{Ou}$ seria mais importante reforçar os elementos do texto ou da pesquisa que marcam sua diferença? Como ao mesmo tempo não mostrar ignorância sobre os modelos já formulados e ser original? Indagações que ampliam a reflexão mais do que propõem respostas.

Nesse cenário vejo a definição de entre-lugar, proposta por Silviano Santiago primeiramente em artigo publicado em inglês em 1971, como um instrumento de conhecimento que expressa a dinâmica que o caracteriza. Trata-se de um processo de conhecimento e não apenas de um conceito. O entre-lugar não é um ponto fixo situado entre dois extremos. André Botelho mostra o movimento contido na expressão que aponta não apenas o fato de o processo de mudança social no Brasil ser marcado pela reiteração e acomodação, mas amplia o sentido de Uma 
literatura nos trópicos. Afirma que seu poder de interpelação "é também de ordem teórica, e pode ser testado na concepção, na feitura do texto e na análise crítica forjadas de um ponto de vista muito próprio" (BOTELHO, 2019, p. 362-363), em que o autor aborda não só a literatura, mas outras linguagens artísticas e culturais.

A categoria analítica entre-lugar, como processo de conhecimento, não nega as descobertas teóricas elaboradas anteriormente e procedentes de vários lugares que nos são ofertadas à reflexão. Não tem como ponto de partida essencializar a particularidade, a diferença, fragmentando, assim, o conhecimento. Não propõe ecletismo somando as diferentes posições teóricas. Ouso afirmar que ressalta a utilização de um terceiro olho como estratégia para garantir um lugar no mundo, e desmistificar as interpretações rotineiras. Trata-se de um instrumento analítico que questiona a concepção de unidade e pureza.

\section{O entre-lugar: texto/contexto}

Considero a proposição entre-lugar a partir da reflexão de Silviano Santiago como estratégia de grande importância para a reflexão sociológica, em especial em sua aplicação à sociologia brasileira, pois possibilita estabelecer relação intrínseca entre a biblioteca e a rua. Isto é: a criação literária, artística, cultural pode trazer elementos totalmente inovadores, mas não parte de um lugar vazio de pensamento e reflexão. Permite dar conta de elementos concretos resultantes do processo social visto tanto à luz das teorias gerais como abre espaço para repensar seu papel na ordenação da sociedade local a partir da herança colonial e sua aclimatação. Em outros termos, mostra que a história não é apenas o cenário em que se desenrolam os acontecimentos, mas componente estrutural do analista de cada situação. Por esse motivo define lugar para o diálogo com outras análises, pois não impõe modelo fechado/único de interpretação.

Certamente o sociólogo vivencia as contradições do espaço e do tempo em que se situa: assim, pode adotar posições que resultam ou no reforço de valores ultrapassados, ou no questionamento deles ou, ainda, na proposição de ângulos novos que o ajudam a visualizar a sociedade, as relações sociais, as instituições, os atores e sua agência. Em outras palavras, é da natureza da sociologia, embora essa regra nem sempre seja cumprida, não se desenvolver segundo dogmas, mas sempre estar aberta a indagações e abrir-se a debates que envolvem conflitos. Ou seja, o sociólogo pode se 
localizar em vários pontos do espectro ideológico, o que resulta que sua análise e, se for o caso suas propostas, assumam efeitos diferenciados entre si em relação à ordenação da sociedade e instituições. Ainda, levando em consideração o desenvolvimento histórico das teorias sociológicas estas podem se dirigir, direta ou indiretamente, ao fortalecimento ou ao enfraquecimento dos interesses dos variados grupos sociais, assumindo perfil normativo, desnudando seu lugar no jogo político.

Dessa perspectiva, me aproprio da fala de Silviano Santiago adaptando-a às ciências sociais:

Entre o sacrifício e o jogo, entre a prisão e a transgressão, entre a submissão ao código e a agressão, entre a obediência e a rebelião, entre a assimilação e a expressão - ali, nesse lugar aparentemente vazio, seu templo e seu lugar de clandestinidade, ali, se realiza o ritual antropófago da [sociologia] latino americana (SANTIAGO, 2000, p. 26).

Não ouso arriscar-me no campo minado da literatura comparada, mas aproveito a ocasião para retomar, do ângulo das ciências sociais, um efeito específico da proposta de Silviano Santiago a respeito da categoria entre-lugar. O importante livro de Erich Auerbach, Mimesis. A representação da realidade na literatura ocidental, publicado em alemão, em 1946, analisa com argúcia os diferentes momentos em que a realidade é abordada pela literatura ocidental, mostrando tanto os pontos comuns como aqueles diferenciados que permitem ler lado a lado o realismo medieval e o moderno. A leitura de Edward Said sobre essa obra coloca sutilmente que a visão "ocidentalista" do autor apresenta limites à sua interpretação, embora reconheça esse texto como uma das maiores obras da crítica literária do século XX. Diz: “A 'representação' da realidade é compreendida por Auerbach como uma apresentação dramática ativa de como cada autor realmente percebe os seres, dá vida às personagens, esclarece o seu mundo." (SAID, 2007, p. 128). Logo em seguida acrescenta que a revelação das articulações do texto esclarece o leitor, mas ao mesmo tempo mostra as reapresentações e interpretações do próprio analista. ${ }^{5}$

\footnotetext{
${ }^{5}$ Said, professor de literatura comparada durante longos anos nos Estados Unidos, é devedor a Auerbach e à sua ideia de representação no redimensionamento que dá à sua carreira ao publicar Orientalismo. O Oriente como invenção do Ocidente, análise importante, fortemente justificada e ancorada na história contemporânea.
} 
Creio que a própria visão/ponto de vista apontados por Said tenha levado Auerbach a excluir Cervantes numa primeira edição do livro, analisando apenas Dom Quixote para a publicação espanhola de Mimesis, em 1949. Assinalo, maldosamente, que o grande crítico não considerava a península ibérica como ocidental. Nem Camões (de Os Lusíadas) nem Fernão Mendes Pinto (de Peregrinação), que têm como tema, cada um a seu modo, as primeiras viagens de caráter conquistador ao Oriente, figuram na sua lista da literatura ocidental.

Creio que a omissão apontada pode ser explicada via leitura atenta ao capítulo "A Dulcineia encantada" (AUERBACH, 1976, p. 299-320). Não entro em pormenores sobre a cuidada análise que aponta mudanças do perfil dos personagens ao longo da aventura, mostrando essas diferenças entre a primeira e a segunda parte de Dom Quixote. No entanto, mesmo as transformações resultantes das relações e das diversas situações são vistas pelo analista como reações às quais "falta inteiramente uma coisa: complicações trágicas e consequências sérias" (AUERBACH, 1976, p. 308). Ressalta sempre o tom de brincadeira que atravessa as situações: "A realidade presta-se a um jogo, que a disfarça a cada instante de maneira diferente; jamais destrói a alegria do jogo com a grave seriedade de suas necessidades, preocupações e paixões." (AUERBACH, 1976, p. 314). Em outras palavras, as situações ambíguas são vistas pelo analista como risíveis, e não trágicas. A tensão presente em cada acontecimento que explicitaria a loucura de Quixote confundindo espaço e tempo, não lhe parece importante como drama ativo, resultante da sociedade espanhola. Não quero multiplicar exemplos, mas o conjunto de considerações leva a que o autor negue a Dom Quixote a qualidade de uma apresentação dramática ativa, pois não é através de suas aventuras "que são descobertos problemas fundamentais da sociedade contemporânea." (AUERBACH, 1976, p. 308).

No entanto, em várias passagens Auerbach refere-se ao fato das ideias de Quixote, pois características da fixação resultante de sua loucura, não apresentarem caráter crítico, sendo que "ele se adapta prazerosamente às circunstâncias"; não havendo "possibilidade de existir qualquer conflito trágico ou qualquer seriedade sombria". Ou ainda, lembra Sancho, que simultaneamente ama e odeia seu amo, mas permanece com ele "porque não encontra outra saída" (AUERBACH, 1976, p. 309-310). No entanto, o crítico refere-se, com certa dificuldade em caracterizá-la, à cena em que Quixote empenha-se em libertar os 
condenados às galés. Revoltado diante da impossibilidade de realizar essa pretensão, o cavaleiro andante afirma que se trata de grave pecado e que Deus, no céu, não se descuida de castigar o mal e premiar o bem. Auerbach não aceita que se atribua essa visão de injustiça como um ataque à ordem jurídica, mas à bondade do personagem que se contenta em não intervir na ordem social. Adapta-se à sua impossibilidade de agir.

Concordo com Auerbach que o caráter trágico não está explícito no texto de Cervantes. Mas essas situações sem saída que se multiplicam no texto não constituem em si o próprio drama? ${ }^{6}$ Trata-se de uma sociedade tão fechada que não permite que escolhas sejam feitas. Nem mesmo pode ser invocada a ordem jurídica, pois as relações sociais e as situações apresentadas indicam o predomínio do arbítrio e não uma sistematização de regras a serem universalmente aplicadas. ${ }^{7}$ Sei que se trata de uma proposição feita a partir de ótica sociológica, mas a diferença entre a apresentação trágica ativa, apontada pelo autor nos livros de Shakespeare ou de Montaigne não está ligada ao contexto inglês ou francês? Cervantes escreve a partir da península ibérica, cuja expansão do império através de suas descobertas marítimas levou Portugal e Espanha a se adiantarem e, posteriormente, a se atrasarem em relação às transformações dos outros países europeus. As colônias, através do exclusivo colonial, instrumento de manutenção da unidade, não teriam levado a que os elementos de diferenciação regional da Espanha - língua e cultura -fossem negligenciados, enquanto os conflitos internos àqueles países citados foram encaminhados racional ou empiricamente? O não direcionamento político dos conflitos na península ibérica não teria atrasado sua "ocidentalização"? E isso não está expresso na ambiguidade das relações, no paradoxo de situações, o que está detalhado no conjunto

\footnotetext{
${ }^{6}$ Caberia aqui, a respeito dessa questão, abordar a relação forma/conteúdo, mas é tema complexo que não ouso desenvolver neste texto.

${ }^{7}$ Ilustração preciosa da condição de arbítrio encontra-se no capítulo "Retórica da verossimilhança" em que Silviano analisa as personagens de Dom Casmurro e de Felix (de Ressureição) mostrando como na sociedade brasileira prevalece a verossimilhança em lugar da verdade. O texto de André Botelho "Sinal dos tempos: anacronismo e atualidade de Uma literatura nos trópicos" retoma o tema e faz análise convincente sobre essa questão e lembra que no Brasil de hoje a retórica da verossimilhança ocupa lugar político importante (BOTELHO, 2019, p. 361-379).
} 
da narrativa de Dom Quixote? ${ }^{8}$ Afinal, a condição colonial dos séculos XVI e XVII, não afetou igualmente metrópole e colônia? A situação sui generis da Espanha e de Portugal no quadro que Auerbach considera literatura ocidental não sugere a necessidade de outro encaminhamento que não apenas a análise textual para explicá-la? Não seria o caso de considerar-se o contexto histórico em que o texto se insere? Esta solução, a meu ver, está presente no procedimento contido na proposta de entrelugar, formulada por Silviano Santiago.

Ao final de "Dulcinéia encantada", Auerbach reafirma que seria ir além da leitura que faz do texto de Dom Quixote considerar a loucura do personagem "simbólica ou tragicamente. " Assim termina:

Uma alegria tão universal e diversificada e, ao mesmo tempo, tão livre e crítica e de problemas na representação da realidade cotidiana constitui uma empresa que nunca voltou a ser tentada na Europa: não posso imaginar onde e quando isso poderia ter acontecido (AUERBACH, 1976, p. 320).

Creio poder afirmar que as discussões de Silviano Santiago nos permitem encontrar, não o que definiria como alegria, mas ironia crítica, ${ }^{9}$ indicando as circunstâncias em que isso se dá. Desse modo, a expressão entre-lugar torna-se instrumento fundamental para compreendermos o lugar da literatura latino-americana no cenário da literatura mundial.

\footnotetext{
${ }^{8}$ No artigo "O reformismo ilustrado luso-brasileiro" Fernando Novais discute a ambivalência presente tanto no pensamento português quanto no brasileiro, mostrando o descompasso entre as ideias e sua aplicação. Em relação à sociedade portuguesa, com claros reflexos na colônia, chama a atenção para duas características conflitantes: de um lado, a precocidade das reformas empreendidas no quadro das conquistas ultramarinas e, de outro, a importação de ideias. O descompasso apontado tem seu fundamente na exiguidade de portadores sociais para as "propostas modernas" (NOVAIS, 1984, p. 105-118). Tive oportunidade de analisar as raízes desse quadro de tensão no pensamento brasileiro em texto anterior (2002).

${ }^{9}$ Aponto o texto de Silviano Santiago, Em liberdade, como exemplar da presença dessa ironia crítica articulando de modo sagaz texto e contexto.
} 


\section{Referências}

AUERBACH, Erich. Mimesis: a representação da realidade na literatura ocidental. 2. ed. São Paulo: Editora Perspectiva, 1976. (Coleção Estudos, v. 2)

BOTELHO, André. Sinal dos tempos: anacronismo e atualidade de Uma literatura nos trópicos. In: SANTIAGO, Silviano. Uma literatura nos trópicos. Recife: Cepe, 2019. p. 261-279. (Edição ampliada)

CORTÁZAR, Julio. 62 modelo para armar. Tradução de Glória Rodríguez. 4. ed. Rio de Janeiro: Civilização Brasileira, 2016.

CORTÁZAR, Julio. O jogo da amarelinha. Tradução de Fernando de Castro Ferro. 2. ed. Rio de Janeiro: Civilização Brasileira, 1972.

LAMBERT, Jacques. Les obstacles au développement provenant de la formation d'une sociéwté dualiste. In: CLAPCS. Resistências à mudança: fatores que impedem ou dificultam o desenvolvimento. Rio de Janeiro: Seminário Internacional CLAPCS, 1959. p. 27- 50.

LAMBERT, Jacques. Os dois Brasis. 3. ed. Rio de Janeiro: Companhia Editora Nacional, 1967.

NOVAIS, Fernando. O reformismo ilustrado luso-brasileiro: alguns aspectos. Revista de História, São Paulo, n. 7, p. 105-118, 1984.

SAID, Edward W. Introdução a Mimesis, de Erich Auerbach. In:

Humanismo e crítica democrática. Tradução de Rosaura Eichenberg. São Paulo: Companhia das Letras, 2007. p. 110-146.

SANTIAGO, Silviano. Em liberdade. Rio de Janeiro: Paz e Terra, 1981.

SANTIAGO, Silviano. Uma literatura nos trópicos. Recife: Cepe, 2019. (Edição ampliada).

SANTIAGO, Silviano. Uma literatura nos trópicos: ensaios sobre dependência cultural. 2. ed. Rio de Janeiro: Rocco, 2000. 